\title{
Students' Perception of Synchronous Courses using Skype-based Video Conferencing
}

\author{
Samar Ghazal ${ }^{*}$, Zarina Samsudin and Hanan Aldowah \\ Centre for Instructional Technology and Multimedia, Universiti Sains Malaysia (USM) \\ Penang, Malaysia; Samar_ghzl@yahoo.com
}

\begin{abstract}
The synchronous model enables teachers and students to communicate in real time, though different spaces. Synchronous distance education offers an environment closer to the traditional class environment and allows students to establish visual and voice communication with teachers through video conferencing. The objective of this study is to determine how postgraduate students' changing perceptions of synchronous distance education classes using Skype-based video conferencing. A qualitative research approach was used for the study. The subjects consisted of students in a Master's program in a public University in Malaysia. For the case study method, a qualitative data collection method was used and the data was obtained via observation results and semi-structured interviews. Data was analyzed using the descriptive analysis method. Findings obtained indicated that students' perceptions of the course changed during and upon the completion of the course. It was generally seen that some of the students knew the accurate concept of synchronous distance education and video conferencing, but they did not use it in their daily lives. Some of them did not have enough information or had preconceived ideas about synchronous communication prior to the course. After attending the online sessions, the perception of students changed and they were able to realize clearly the opportunities that are provided by synchronous education via the Internet. In this study, the most important problem in synchronous distance education was determined to be disconnection and audio problems. Other significant problem related to hardware includes - i.e., sound, speed and connectivity issues. At some point students became bored because they could not see each other by video call due to the limitation of the Skype program. Besides technical problems, students expressed that the factors of time management and environment also change their perceptions on synchronous distance education. The paper suggests possible positive changes in the students' opinions about synchronous distance education and more fruitful courses should be provided on condition that some of the factors causing the negative perceptions are minimized.
\end{abstract}

Keywords: Distance Education, Skype, Synchronous Learning, Video Conference

\section{Introduction}

In recent years, developments occurring in Internetbased technologies have allowed/enabled the e-learning model to be an important factor in distance education ${ }^{1}$. According to ${ }^{2}$, e-learning is an approach to enhance and facilitate education via both communication technologies and computer. E-learning, defined as an education based on media and electronic tools through network technologies and the Internet. E-learning offers a model of an alternative education, combining together students and teachers from different environments ${ }^{3}$. The communication in e-learning model is implemented by two different methods, asynchronous and synchronous.

The synchronous model enables students and teachers to communicate at the same time in spite of different places. The asynchronous model does not require the student and teacher to communicate in real time. It provides learners with the flexibility to complete his/her learning based on his/her own learning speed and time $e^{4,5}$.

${ }^{*}$ Author for correspondence 
Synchronous distance education is considered more useful in terms of real-time discussion, dealing with technical issues and brainstorming. Synchronous distance education offers an environment closer to the traditional class environment and allows immediate feedback. In contrast, in asynchronous distance education delayed in the feedback may cause lower levels of interaction, interest and engagement among students. In addition also make students feeling a sense of isolation ${ }^{1,6}$. Pointed out that the environment in synchronous distance education is closer to the traditional class, where the synchronous distance education allows the students and teachers to establish audio and video communication through video conferencing.

Video conferencing is one of the technological systems which can be used in online learning ${ }^{7}$. Video conferencing is a synchronous model for interactive video, audio and data transfer conducted between two or more groups/people through communication lines ${ }^{8}$. The effectiveness of video conferencing as an educational tool relies on several factors, such as institutional, contextual and the attitudes of students and teachers ${ }^{7}$. Video conferencing has advantages in terms of save time and reduce cost of education by connecting teachers and students who are in different locations. Video conferencing offers a connected environment where students can share their experiences with each another and creates a feeling of togetherness, besides the benefit of expert instruction. Video conferencing is considered more advanced compared to other methods of distance education in terms of real-time interaction, relationships and motivation cooperative learning ${ }^{9,10}$. The quality of video conferencing systems differs depending on the bandwidth and technology used and it affects the quality of education and level of interaction among students and teachers ${ }^{11}$. In addition, it promotes effective student participation in the process is very important for ensuring training environment and an efficient education ${ }^{12}$.

A repeated error in evaluating video conferencing practices is to equate the online environment with the traditional class environment and use it in this way ${ }^{13}$. While the practices of video conferencing provide opportunities for synchronous listening, watching and communication with other participants, however the human interaction is not efficient as in the process of the traditional education $^{14}$. In order to assess the efficiency of video conferencing in education, many studies that have been submitted indicate that the participants' expectations still cannot be realized adequately. The perceptions of students are accepted as one of the determinants in order to develop knowledge ${ }^{15}$. The students mentioned that the technologies applied technical problems such as image, sound and connection problems, the interaction between students and the duration of the courses were factors that affected on their perceptions and viewpoints about distance education ${ }^{1,6,16}$.

Skype is free software for communication that permits users to perform calls, video conferencing online and send instant messages. It is easy to use and install. Skype program is considered as one of the best voices-over-internet services online. Skype is one of the applied programs that can be used to broaden collaboration and interaction with different groups involved in the learning process. Internet Forums and E-mail are popular forms of asynchronous communication for the educational process. In contrast, video conferencing, chat and voice calling features in the Skype program allow for synchronous communication. These main features of the Skype program break the barriers of the traditional classroom walls to overcome the distance that frequently restricts participants from universal communications ${ }^{17}$.

The objective of this study is to investigate postgraduate students' perceptions on Synchronous courses using Skype-based Video Conferencing. The questions of the study are:

- What are the students' opinions about synchronous education before taking online sessions using Skypebased Video Conferencing?

- What are the students' opinions about synchronous education after taking online sessions using Skypebased Video Conferencing?

- What are the positives and negatives factors of synchronous distance education?

- What impacts the perception of students toward distance education during the learning process?

\section{Literature Review}

A study carried out by ${ }^{18}$ titled "Quality of Teaching and Learning via Video Conferencing" investigated the concern of using video conferencing on the classroom activities and cognitive outcomes among local and remote students. The study's subjects consisted of a total of 66 students enrolled for the master degree course. Forty five students participated in local site and 21 in remote sites. 
The study indicated that the technical problem related to the hardware made the students in remote sites could not make eye contact with other students and among teachers. As a result the students felt alone (isolated) and not a part of the class. This situation would the decrease of the concentration of students and made a negative perception of their learning. The results indicated if there is a good working relationship between the organizers in both the local and remote sites. The video conferencing would be used properly and applied effectively. The factors of the lack of the equipment, inexperienced, bad preparation and planning, inappropriate teaching strategies and inadequate training also have a negative impact on the quality of learning and teaching via video conferencing.

In the study, "Perceptions of Students Who Take Synchronous Courses through Video Conferencing about Distance Education"1, examined that the perceptions of undergraduate students toward video conference-based lecture via distance education changed. The interviewers were conducted with nine students from two different levels.

The study concluded that negative perceptions of the students started to turn into more positive towards the end of the video conferencing. The students' interviews showed that five main factors that were technical problems, the teachers, environments, course type and duration also caused a change in their perceptions.

The study conducted by ${ }^{7}$ aimed to find out students' perceptions of video conferencing in higher education. The study was conducted with 36 students. The students stated that they had positive perceptions of a video conferencing. The participants mentioned that one of the advantages of video conferencing was online interaction. Also the students thought that prior experiences in video conferencing were important. The participants noted that video conferencing had more benefits for educations in terms of being able to share ideas, learning new information and feeling relaxed, benefiting from experts and creating a new learning. In spite of these advantages, the technical problems and the topic of the lecture might cause a slight change to negative perceptions of students toward video conferencing. If the video conferencing session were organized at frequent intervals, then the perceptions of students began to turn into more positive rather than negative.

In the study, "The Value of Using Synchronous Conferencing for Instruction and Students ${ }^{19}$ " showed that the participants had a positive perception toward video conferencing. But other students confirmed that video conferencing could not replace face to face traditional classes due to technical problems. The study identified the quality of video and audio was considered as critical factors for successful video conferencing courses. Also the results indicated that synchronous video conferencing provided immediate feedback and interaction between instructors and students with audio and video but the difficulty in agreeing on the scheduling of meeting times remains an issue.

In the study ${ }^{6}$ focused on the students' experiences who were taking courses through video conferencing during one year in the field of initial training for teachers. After conducting the interviews, the participants mentioned that the technical errors that occurred in the video, internet connection and sound made the participants feel as if they were not as real students in the class. Furthermore, conducting the interview with the teacher through a specific period of time is considered as deficiency. Most of the students frequently mentioned that there were live interaction among students and teachers, creating a sense of intimacy and receiving immediate answers about questions in the courses.

\section{Methodology}

\subsection{Research Design}

This study used a qualitative approach as described by ${ }^{20}$. The qualitative approach is sensitive for the environment of natural and the researcher has a participation role. The qualitative approach is flexible in the research design and is considered as an integrated approach. It reveals about the perceptions of participants for conducting the study and it has an inductive analysis ${ }^{21}$. The case study was used in the research design. The case study model gives detailed, in-depth and rich data collection about an event or phenomenon ${ }^{22}$.

\subsection{Participants of the Study}

The participants for the study were twenty students of postgraduate students enrolled in web based training and management course in Master's program in the public University at Malaysia. During this course there were online sessions. The participants attended an online session using Skype program. These online sessions were for three weeks. The participants were meeting online once per week for approximately two hours. The participants 
never met face-to-face during the online sessions. These participants were chosen in order to determine how postgraduate students change their perceptions about synchronous education using Skype-based Video Conferencing. According to the research ethics, the participants' names were not used in the study. Students participating in the study were encoded as "P1, P2, P3, P4, P5, P6, P7, P8, P9, P10, P11, P12, P13, P14, P15, P16, P17, P18, P19 and $\mathrm{P} 20$ ".

\subsection{Data Collection and Analysis}

Multiple data collection methods were used to enable corroboration of the data. In this research, observation and semi-structured interviews were used as data collection tools. In this method, the researcher tried to identify some of mental perceptions unobservable, comments and opinions of participants about the study, reactions. Interview questions regarding the study show in the Table 1.

Table 1. Interview question

\begin{tabular}{|l|l|}
\hline Number & Related Interview Questions \\
\hline 1. & $\begin{array}{l}\text { What are the opinions of students about distance } \\
\text { educations before taking synchronous distance } \\
\text { education through a video conference via Skype? }\end{array}$ \\
\hline 2. & $\begin{array}{l}\text { What are the opinions of students about distance } \\
\text { educations after taking synchronous distance edu- } \\
\text { cation through a video conference via Skype? }\end{array}$ \\
\hline 3. & $\begin{array}{l}\text { What are the positives and negatives of synchro- } \\
\text { nous distance education }\end{array}$ \\
\hline 4. & $\begin{array}{l}\text { What impacts the students' perceptions of dis- } \\
\text { tance education during the educational process? }\end{array}$ \\
\hline
\end{tabular}

This study uses the descriptive analysis technique in the analysis of the data obtained through interviews. Within the framework interviews, the researcher has coded the transcripts for each participant by repeatedly reading and formation of the themes. In addition, the researcher supported the themes through reflection of views by citing directly from participants' opinions. The researchers use the code names instead of real names in the quotations.

\section{Finding}

This section shows the findings about the perceptions of postgraduate students toward synchronous distance education using Skype-based video conferencing and the factors that caused changing in their perceptions. Research questions were analyzed and examined accurately within the framework of participants' view points. Opinions and themes about each question in addition to data related to the study were observed in the research process and are presented below, in the forms of observation.

Data relating to the questions "What are the students" opinions about synchronous education before taking online sessions using Skype-based Video Conferencing?" and "What are the students' opinions about synchronous education after taking online sessions using Skypebased Video Conferencing?" are presented below. From the results of the study about the participants' opinions on the synchronous distance education before taking online course using Skype-based video conferencing, it seems that the majority of the participants believed that synchronous distance education courses might be just listening to lectures and exchanging ideas in a simple way. Although the participants think synchronous online learning is a useful way of learning. Some of the participants thought that online video conferencing required that the students need to meet online face to face before that. Two of the participants mentioned that synchronous distance education is very flexible and is considered as a new learning style but still cannot substitute traditional course. Only three participants mentioned that synchronous distance education is a simultaneous and interactive education conducted via the Internet. The participants' opinions below:

- "First one I thought was an online video conferencing meeting where everyone have to online face to face before that, each one of them have to agree with the meeting time." (P12)

- "Ifeel this is learning style is very flexible, but not as the traditional class..........." (P4)

- "I think it's a good way of thinking, but I don't think it can substitute traditional course." (P3)

- "I think that the students are able to interact with each other more, compare to the traditional learning method at the same time on different place". (P6)

From the participants' opinions, it seems that the majority of the participants do not have an exact concept about synchronous distance education and the benefits of this learning. Some of them were the first time using Skype-based video conferencing. Some of them know about the video conferencing but they did not use it in real experiences. Comments, below: 
- “Actually I really don't have any idea about synchronous learning before taking online sessions before the online session. I think have an idea that it's I normal learning system". (P5)

- "I have no experience previously. This is my first experience using Skype." (P8)

Although a majority of participants did not have an accurate concept of synchronous distance education but a few of participants used video conferencing before that in their work, education, life, etc. They considered the Skype program is the best way of communication between their peers, classmates, coworkers, family, etc. Participants' opinions below:

- "I have used Skype to communicate with peers and long lost friends. Most of the time was the 1 to 1 conversation". (P9)

- "I have used the video conference when I was studying at UMS for my first degree. That time, this technology is really very new to me because I never used it before. "( $\mathrm{P} 4)$

Since a majority of the participants do not have an accurate concept of synchronous distance education, but they believe that they will experience connectivity issues that may prevent them from learning or cause boredom, possibly even causing anxious them to fail the course:

- "I was anxious that we would not be able to continue the course when connections failed......" (P4)

Beside the concerns of the participants above-mentioned, they also observed that they were excited and concerned about the environment when they knew that they would take online sessions using Skype-based video conferencing. One participant mentioned that he felt anxious due to his concerns of the programs used and devices settings. Comments below:

- "I feel uncomfortable because the lack of fast internet despite I have a well equipped PC with Webcam "(P1)

- "I feel anxiety because I'm not familiar with using Skype and I should to learn how to use Skype and its features". (P3)

After taking online sessions using Skype-based video conferencing for three times, participants defined this concept as a method of learning realized through enabling teachers and students to communicate in real time though different places. Some of the participants said that synchronous distance education offering an environment closer to the traditional class environment and allowing instant feedback. Another mentioned that this type of education is not the same as face-to-face education in terms of communication and interaction. Two of the participants said that the online discussion could promote activation and motivation participants between each other to interact more. Opinions of the participants below:

- “......., it's really a valuable experience. This kind of learning style is a different learning style and very efficient. (P4)

- "..... the students are able to interact with each other more compare to the traditional learning method. We were able to get feedbacks instantly from different sources" (P6)

The participants feel that the experience of learning in the synchronous online course is enjoyable, comfortable and convenient, because they do not need to come to the physical campus and can be more relaxed during the class. Majority of Participants pointed out that synchronous online education has features in terms of being able to participate the experts in a course from different places, comfortable and interesting environments, learning new information in the technology, saves time for teachers and students, saves travel expenses, providing interactive environments, encourages the teamwork and ensuring quick access to information:

- "These web training lessons is very interesting and widen our horizon on the latest tool in education as well as communication". (P3)

- "For these three weeks I'm just staying at my home, didn't travel to the university. So, it saves my travel expenses". ( $\mathrm{P} 4)$

In spite of all of these advantages, the participants mentioned that a big challenge was the communication issue. The synchronous distance education lacks to the facial expression this makes it difficult for the participants to grasp what other participants are saying. Opinions of the participants below:

- "I consider the weakness of communication as a great deficiency“. (P2) 
- "To talk about disadvantages, we can mention the weakness of communication". (P4)

Beside the issue mentioned above, technical problems also can weaken the learning process. Majority of participants indicated that they disliked technical problems. Some of the participants complained about poor sound and video quality.

Some students asserted that the virtual conferencing tools did not serve as a direct replacement for face to face course because of technical problems. As a result of the technical problems, some students preferred face to face classes. Comments below:

- "For our conference, we couldn't use video conference because we need to purchase the full premium of SKYPE. Sometime, we have some internet connection problems". (P4)

- "I think the technical problem is the greatest disadvantage". (P8)

- "Sometimes I need to make call for the same persons over and over again due to line interruption". (P17)

Besides the technical problems, the time management also was the problem for the participants. Some of the participants mentioned that the problem with synchronous learning is to gather the participants at the same time. Majority of the participants agreed that whenever the number of participants has increased in the same group whenever the problems were more. Opinions of the participants below:

- "Sometimes it is quite difficult to agree to a time for meeting because each of us got our own activities on". (P5)

- "I think the Skype have problem or the quality will go worst when big number of people in group". (P9)

Data relating to the question "What impacts the students' perceptions of distance education during the educational process?" are presented below.

From the participants' opinion, there are four main factors affecting on participants' perceptions.

\section{Technical Problems}

By examining the table presenting the factors that affected the participants' perceptions of Synchronous Courses Using Skype-based Video Conferencing, it was determined that they faced a communication gap because of connection problems that caused cuts in the sound and image. Furthermore, the participants stated that they encountered problems such as not seeing each other clearly and not making eye contact by video call because they need to purchase the full premium of Skype program. The participants' opinions about these issues are given below.

- “......the problem that I faced whereby ..... Video images weren't clear. Maybe it was due to the line reception or some technical problem " (P14)

- "The only problem on using Skype is the Internet connection. It has to be fast so that ............."(P15)

- "There was no much trouble, but the problem was the internet connection. The image display was very slow "(P13)

- "Sometimes I need to make call for the same person over and over again due to line interruption"(P17)

\section{Medium}

The participants liked the environment of synchronous learning and availability of technological devices. The participants used their computers in their home which makes them more comfortable. They are satisfied learning new information from the specialists in a more comfortable environment than the conventional class environment. As well as there are some difficulties faced in the communication between each other by video conferencing because of certain environmental factors such as limitation of the Skype program, speed of Internet lines and the difference in the hardware specifications among the participants. The opinions of the participants are as follows:

- "This medium will also allow those shy students to have the chance to build their confidence in communication". (P20)

- ".......... if a student did not have the good tool to communicate than it will be useless". (P11)

- "For these ten weeks I'm just staying at my home, I felt comfortable".(P3)

- "I often informed that the quality of image is low because the limitation of group calling". (P10)

\section{Time Management}

The Participants said that the difficulty of agreement on the time for online sessions would affect on flexibility learning in the synchronous distance education via video 
conferencing. The majority of the participants stated that the problem was how to determine and manage the time that fit with all the participants. The opinions of the participants are as follows:

- "Sometimes it is quite difficult to agree on a time for meeting because each of us got our own activities on." (P3)

- "We found a problem that two of our group forgot the time of our discussion". (P2)

- "..... it is not flexible, because everyone have their busy schedule and they have to arrange their time for learning". (P19)

- "...... The problem is to gather the participants at one time, so that none of them will miss the discussion". (P13)

Table 2. Factors influencing perceptions of synchronous distance education In the light of the findings above, the factors affecting participants' perceptions on synchronous distance education during the learning process can be summarized in Table2.

\begin{tabular}{|c|c|c|c|c|}
\hline & Technical Problems & Medium & Time management & Number Of Participants \\
\hline P1 & $\begin{array}{l}\text { Sound problem } \\
\text { Connection problem } \\
\text { Unable to see each other } \\
\text { in video }\end{array}$ & $\begin{array}{l}\text { Comfortable environment } \\
\text { Need to buy the original version. }\end{array}$ & $\begin{array}{l}\text { Unable to manage } \\
\text { the time. }\end{array}$ & $\begin{array}{l}\text { Appropriate with small number of } \\
\text { participants }\end{array}$ \\
\hline $\mathrm{P} 2$ & Video problem & Need to buy the original version. & $\begin{array}{l}\text { Unable to control the } \\
\text { time. }\end{array}$ & Many responses make confuse \\
\hline P3 & $\begin{array}{l}\text { Sound problem } \\
\text { Connection problem }\end{array}$ & Comfortable environment & & \\
\hline P4 & $\begin{array}{l}\text { A voice interrupts } \\
\text { Connection problem }\end{array}$ & --. & $\begin{array}{l}\text { Unable to manage } \\
\text { the time. }\end{array}$ & Many responses make confuse \\
\hline P5 & $\begin{array}{l}\text { Audio echo } \\
\text { Connection problem }\end{array}$ & $\begin{array}{l}\text { Comfortable environment } \\
\text { Need to buy the original version. }\end{array}$ & $\begin{array}{l}\text { Unable to control the } \\
\text { time. }\end{array}$ & $\begin{array}{l}\text { Appropriate with small number of } \\
\text { participants }\end{array}$ \\
\hline P6 & Technical Problem & The Technologies used & 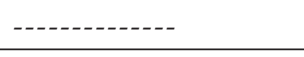 & Many responses make confuse \\
\hline P7 & $\begin{array}{l}\text { Internet Connection } \\
\text { Voice Interruption }\end{array}$ & $\begin{array}{l}\text { Comfortable environment } \\
\text { Need to buy the original version. }\end{array}$ & $\begin{array}{l}\text { Unable to manage } \\
\text { the time. }\end{array}$ & $\begin{array}{l}\text { Small number of participants make } \\
\text { easy to control everything }\end{array}$ \\
\hline P8 & $\begin{array}{l}\text { Connection problem } \\
\text { Eye - Contact problem } \\
\end{array}$ & $\begin{array}{l}\text { Comfortable environment } \\
\text { Need to buy the original version }\end{array}$ & & $\begin{array}{l}\text { Small number of participants make } \\
\text { easy to make video call }\end{array}$ \\
\hline P9 & $\begin{array}{l}\text { Low Connections } \\
\text { Unable to see each others }\end{array}$ & The Technologies used & $\begin{array}{l}\text { Difficulty to agree } \\
\text { on time }\end{array}$ & \\
\hline P10 & $\begin{array}{l}\text { Quality of image is low } \\
\text { Internet Interruption }\end{array}$ & $\begin{array}{l}\text { Limitation of group calling } \\
\text { The Technologies used }\end{array}$ & $\begin{array}{l}\text { Unable to manage } \\
\text { the time. }\end{array}$ & $\begin{array}{l}\text { Small number of participants make } \\
\text { easy to control everything }\end{array}$ \\
\hline P11 & $\begin{array}{l}\text { Delay in sound } \\
\text { Eye - Contact problem } \\
\end{array}$ & $\begin{array}{l}\text { Comfortable environment } \\
\text { Need to buy the original version }\end{array}$ & $\begin{array}{l}\text { Difficulty to agree } \\
\text { on time }\end{array}$ & $\begin{array}{l}\text { Appropriate with small number of } \\
\text { participants }\end{array}$ \\
\hline $\mathrm{P} 12$ & Technical problem & - & $\begin{array}{l}\text { Unable to control the } \\
\text { time }\end{array}$ & $\begin{array}{l}\text { Many participants, everything will } \\
\text { mess up }\end{array}$ \\
\hline P13 & $\begin{array}{l}\text { Voice Interruption } \\
\text { Connection problem }\end{array}$ & $\begin{array}{l}\text { Quality of programs used, } \\
\text { computers and Internet }\end{array}$ & $\begin{array}{l}\text { Unable to manage } \\
\text { the time }\end{array}$ & $\begin{array}{l}\text { Appropriate with small number of } \\
\text { participants }\end{array}$ \\
\hline
\end{tabular}




\begin{tabular}{|c|c|c|c|c|}
\hline P14 & $\begin{array}{l}\text { Video problem } \\
\text { Connection problem } \\
\text { Internet Interruption }\end{array}$ & $\begin{array}{l}\text { Comfortable environment } \\
\text { Need to buy the original version } \\
\text { The Technologies used }\end{array}$ & $\begin{array}{l}\text { Difficulty to agree } \\
\text { on time }\end{array}$ & 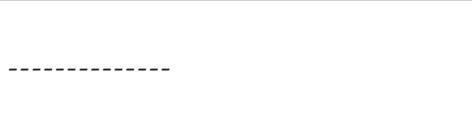 \\
\hline P15 & $\begin{array}{l}\text { Internet Connection } \\
\text { Video problem }\end{array}$ & $-\cdots$ & $\begin{array}{l}\text { Unable to manage } \\
\text { the time }\end{array}$ & $\begin{array}{l}\text { Small number of participants make } \\
\text { easy to understand the content }\end{array}$ \\
\hline P16 & $\begin{array}{l}\text { Internet Connection } \\
\text { Eye - Contact problem }\end{array}$ & $\begin{array}{l}\text { Quality of programs used, com- } \\
\text { puters and Internet } \\
\text { Comfortable environment }\end{array}$ & 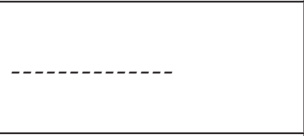 & $\begin{array}{l}\text { Appropriate with small number of } \\
\text { participants }\end{array}$ \\
\hline $\mathrm{P} 17$ & $\begin{array}{l}\text { Video problem } \\
\text { Internet Connection } \\
\text { Line Interruption } \\
\end{array}$ & $\begin{array}{l}\text { Comfortable environment } \\
\text { Need to buy the original version } \\
\text { The Technologies used }\end{array}$ & $\begin{array}{l}\text { Difficulty to agree } \\
\text { on time }\end{array}$ & $\begin{array}{l}\text { Small number of participants make } \\
\text { easy to control everything }\end{array}$ \\
\hline P18 & $\begin{array}{l}\text { Voice problem } \\
\text { Internet Connection }\end{array}$ & $\begin{array}{l}\text { Comfortable environment } \\
\text { Quality of programs used, com- } \\
\text { puters and Internet }\end{array}$ & $\begin{array}{l}\text { Unable to control the } \\
\text { time }\end{array}$ & $\begin{array}{l}\text { Small number of participants make } \\
\text { easy to understand the content }\end{array}$ \\
\hline P19 & $\begin{array}{l}\text { Connection Interruption } \\
\text { Voice problem }\end{array}$ & $\begin{array}{l}\text { Comfortable environment } \\
\text { Need to buy the original version }\end{array}$ & $\begin{array}{l}\text { Difficulty to agree } \\
\text { on time }\end{array}$ & $\begin{array}{l}\text { Small number of participants make } \\
\text { easy to control everything }\end{array}$ \\
\hline P20 & $\begin{array}{l}\text { Sound problem } \\
\text { Eye-contact problem }\end{array}$ & $\begin{array}{l}\text { Comfortable environment } \\
\text { The Technologies used }\end{array}$ & $\begin{array}{l}\text { Unable to control the } \\
\text { time }\end{array}$ & ------------- \\
\hline
\end{tabular}

\section{Discussion and Conclusion}

According to the Findings obtained, the following results can be reached. The objective of this study is to investigate how postgraduate students are changing their perceptions of Synchronous courses using Skype-based Video Conferencing. In addition to discover how postgraduate students perceive learning through taking Synchronous courses using Skype-based Video Conferencing.

The researchers observed that participants have previous biases about the concept of synchronous distance education, because they did not have accurate information about the synchronous distance education or they had misinformation. However it was clear from the interviews that these perceptions began to change positively with the opportunities offered by the synchronous distance education, which is in line with other studies $^{7,11}$.

The highlight of research indicated four critical factors that cause changes in the participants' perceptions on synchronous distance education. These factors are defined as following: technical problems, the environment, the time management and the number of participants.

In this research, technical problems take the lead among the factors that affecting on the perceptions of participants. Participants had negative perceptions about technical faults such as cuts and echoes of the sound, fail to connect by video call and internet connection that distracted them online session. In the study ${ }^{6}$ stated that faulty technology caused participants to feel as if they were not real students which is a consistent finding with ${ }^{23}$. Similar to the finding reported by ${ }^{19}$ the participants had positive perceptions in using synchronous distance education, but technical problems were still the largest barrier to type distance learning. Also this conclusion is similar to the study carried out by ${ }^{1}$. In addition, other result obtained is that the participants could not see each other by video call due to the limitation on the Skype program. And thus the participants had difficulty in creating eye contact with each others; therefore this has adversely affected their motivation. This result is similar with ${ }^{1}$. The technical problems factor has affected negatively on participants' perceptions about synchronous distance education.

According to the results both of ${ }^{11,16}$, it was also observed that participants liked the educational environments that used new technologies. In addition to the ${ }^{1}$ stated that the insufficiency of this technologies caused students to feel disappointed in the courses. The same results were obtained in the present study where participants stated that failure to make video calls and transform for voice calls affected them negatively. In addition the perceptions of students might turn into being more positive rather than negative if the video conferencing session could have been organized at the right time for all participants in an appropriate environment, which is in consistent with ${ }^{7}$ study.

When examining the factors that affecting the participants' perceptions of synchronous distance education 
via video conference, we noted that there were positive changes in the opinions of the participants about distance education and more fruitful courses will be provided on condition that the factors causing negative perceptions are minimized. For further research with larger samples and more video conferencing sessions is necessary to gain a more in-depth understanding into participants' perceptions and explain the reasons behind their opinions.

\section{Reference}

1. Karal H, Cebi A, Turgut YE. Perceptions of students who take synchronous courses through video conferencing about distance education. Turkish Online Journal of Educational Technology-TOJET. 2011 Oct; 10(4):276-93.

2. Erah P, editor. Introduction to e-learning protocols. ETF capacity building workshop for lecturers of Universities in Nigeria at the University of Uyo (2006, September 26); 2006.

3. Driscoll M. Web-based training: Creating e-learning experiences. John Wiley \& Sons; 2010.

4. Horton WK. Designing web-based training: How to teach anyone anything anywhere anytime. Wiley New York, NY; 2000 Feb.

5. E-Learning MR. Strategies for delivering knowledge in the digital age. McGraw-Hill; 2001.

6. Gillies D. Student perspectives on videoconferencing in teacher education at a distance. Distance Education. 2008; 29(1):107-18.

7. Candarli D, Yuksel HG. Students' perceptions of video-conferencing in the classrooms in higher education. ProcediaSocial and Behavioral Sciences. 2012 Feb; 47:35761.

8. Gough M. Video Conferencing over IP: Configure, secure and troubleshoot. Configure, Secure and Troubleshoot: Elsevier; 2006.

9. Wheeler S, Amiotte S. The death of distance: Documenting the effects of distance education in South Dakota. Turkish Online Journal of Distance Education. 2005; 6(1).

10. Bates AT. Technology, e-learning and distance education. Routledge; 2005.
11. Martin M. Seeing is believing: the role of Video Conferencing in distance learning. British Journal of Educational Technology. 2005 May; 36(3):397-405.

12. Newman DL. Video conferencing Technology in K-12 Instruction. Best Practices and Trends: Best Practices and Trends: IGI Global; 2007.

13. Anastasiades PS, Filippousis G, Karvunis L, Siakas S, Tomazinakis A, Giza P, et al. Interactive Video conferencing for collaborative learning at a distance in the school of 21 st century: A case study in elementary schools in Greece. Computers and Education. 2010 Feb; 54(2):321-39.

14. Schweizer K, Paechter M, Weidenmann B. Blended learning as a strategy to improve collaborative task performance. Journal of Educational Media. 2003; 28(2-3):21124.

15. Simsek A. The wholeness teaching in history lessons: A perspective essay from Gestalt approach to Holistic approach. International Journal of Human sciences. 2008; 5(2).

16. Marsh B, Mitchell N, Adamczyk P. Interactive video technology: Enhancing professional learning in initial teacher education. Computers and Education. 2010 Apr; 54(3):7428.

17. Wanda DC. Using Skype to increase Educational Communication. 2007. Available from: http://etec.ctlt.ubc.ca/510wiki/ Using_Skype_to_Increase_Educational_Communication.

18. Knipe D, Lee M. The quality of teaching and learning via video conferencing. British Journal of Educational Technology. 2002 Jun; 33(3):30111.

19. Grant MM, Cheon J. The value of using synchronous conferencing for instruction and students. Journal of Interactive Online Learning. 2007; 6(3):211-26.

20. Creswell JW. Research design: Qualitative, quantitative and mixed methods approaches: Sage publications; 2013.

21. Yildirim A, Simsek H. Qualitative research methods in social sciences. Ankara: Seckin Publishing; 2005.

22. George AL, Bennett A. Case studies and theory development in the social sciences. Mit Press; 2005.

23. Koppelman H, Vranken H. Experiences with a synchronous virtual classroom in distance education. ACM SIGCSE Bulletin; 2008. p. 194-8. 